\title{
ESTRATÉGIAS PEDAGÓGICAS CONTRA A PRÁTICA DO BULLYING NA ESCOLA
}

\author{
Cleonildo de Lima Campos ${ }^{1}$ \\ Silvaneide da Silva Vieira ${ }^{2}$ \\ Rosecler de Carvalho Senra Santos ${ }^{3}$ \\ Abilene San Martin de Souza ${ }^{4}$ \\ Juliana Patrícia Silva de Souza ${ }^{5}$ \\ Marilce Aparecida Saldanha de Carvalho ${ }^{6}$ \\ Maria Ângela de Farias Pinho ${ }^{7}$
}

RESUMO: O presente artigo tem como objetivo conceituar e compreender a importância do lúdico na Educação Infantil, como ferramenta fundamental para o desenvolvimentoda criança na educação infantil. Justificando a escolha do tema, partiu de uma necessidade levantada dentro das práticas do estágio supervisionado I, ondealgumas escolas não proporcionam a essa criança uma metodologia de ensino prazerosa, em busca de novas experiências que proporcionem a construção do processo de ensino aprendizagem. Quando a metodologia escolhida, será dividia em dois momentos, onde o primeiro momento se refere a escolha da metodologia que foi a pesquisa de cunho indutivo, realizando a pesquisa bibliográfica, em revistas eletrônicas especializadas no assunto, como em artigos e também em periódicos, além da consulta em bibliotecas virtuais de grandes universidades brasileiras, especializadas, juntamente com publicações físicas presentes no mundo acadêmico. O referido trabalho será dividido em três partes; sendo que em um primeiro momento abordará a história da educação infantil no Brasil atribuindo também a visão sob criança durante a evolução do processo histórico daeducaçãoinfantil brasileira; o segundo momento relata a concepção do Lúdico na perspectivade alguns autores, tratando o lúdico como principal ferramenta de aprendizagem na

\footnotetext{
${ }^{\text {I }}$ Bacharel em direito pela UNIC (universidade de cuiabá), licenciado em pedagogia pelo Centro Universitário UNINTER, pós-graduado em educação infantil e psicopedagogia pela Faculeste.

2 Licenciatura em pedagogia pela FEICS- Faculdades Evangélicas Integradas Cantares de Salomão). Especialização em Educacao Infantil com ênfase em Educação Especial. AVEC Faculdades Integradas de Várzea Grande.

3 Faculdade de licenciatura plena em pedagogia realizada na Universidade Federal do Mato Grosso- UFMT. Especialização em Educação Infantil realizada na UFMT. Especialização em psicopedagogia realizada na FAUC. 4 Licenciatura em pedagogia pela FEICS- Faculdades Evangélicas Integradas Cantares de Salomão. Especialização em Educacao Infantil com ênfase em Educação Especial. AVEC Faculdades Integradas de Várzea Grande.

5 Licenciada em pedagogia pela UNIVAG- Universidade de Várzea Grande

${ }^{6}$ Formada em pedagogia e professora na rede municipal de Cuiabá.

7 Graduação em Licenciatura em Pedagogia e Licenciatura plena em matemática

Pós- graduação em Educação de Jovens e Adultos.Pós- graduação em Educação Infantil
} 
Educação Infantil; através jogos e brincadeiras como metodologia auxiliadora na construção do processo de ensino-aprendizagem; para finalizar o terceiro momento relata-se sobre a importância do lúdico na educação Infantil. Uma Pesquisa baseada no pensamento de alguns autores como, Aries (198I), Lopes (2005), Kuhlmann (2005), Farias (2005), Rizzo (1997) e Ferreira (2003). Dessa forma, conclui-se que, construir um ensino de qualidade auxiliando e reconhecendo os direitos das crianças em seu processo de ensino e aprendizagem, permitindo que essa criança trilhe novos caminhos em busca de novas experiências com a aprendizagem.

Palavras-chave: Lúdico. Educação Infantil. Ensino. Aprendizagem.

ABSTRACT: The present aims to conceptualize and understand the importance of the playful in Child Education as a fundamental tool for the development of children in early childhood education. Justifying the choice of theme, it started from a need raised within the practices of supervised internship I, where some schools do not provide this child with a pleasant teaching methodology, in search of new experiences that provide the construction of the process of teaching learning. When the methodology chosen, it will be divided into two moments, where the first moment refers to the choice of the methodology that was the inductive research, carrying out the bibliographic research, in electronic journals specialized in the subject, as in articles and also in periodicals, besides of the consultation in virtual libraries of great Brazilian universities, specialized, together with physical publications present in the academic world. This work will be divided into three parts; being that in a first moment it will approach the history of the infantile education in Brazil also attributing the vision under child during the evolution of the historical process of the Brazilian infantile education; the second moment relates the conception of the Lúdico from the perspective of some authors, treating the play as the main learning tool in Early Childhood Education; through games and games as a supporting methodology in the construction of the teaching-learning process; to conclude the third moment it is reported on the importance of the playful in the Infantile education. A research based on the thinking of some authors such as Aries (198I), Lopes (2005), Kuhlmann (2005), Farias (2005), Rizzo (1997) and Ferreira (2003). Thus, we conclude that, to build a quality teaching aiding and recognizing the rights of children in their teaching and learning process, allowing this child to find new ways in search of newexperiences with learning.

Keywords: Playful. Child education. Teaching. Learning.

\section{INTRODUÇÃO}

Sabemos bem a importancia da inclusão do ludico na educação, principalmente na vida infantil das crianças e adolescentes. O Lúdico na educaçãoinfantil é uma ferramenta 
importantissima no processo de ensino e aprendizagem epodemos destacar que o Lúdico continua sendo um desafio cada dia mais presente na prática educacional no seio escolar.

Apesar de estarmos vivendo no século XXI podemos observar que existe algumas escolas ainda funcionam no antigo sistema tradicional de ensino, onde a criança é privada dos jogos e brincadeiras, ou seja, um ensino mecânico onde a repetição, acaba não sendo algo prazeroso na vida escolar das crianças.

O objetivo do presente trabalho de conclusão de curso, é de conceituar e compreender a importância da ludicidade na educação infantil, como ferramenta para a construção do processo de ensino-aprendizagem, proporcionando as crianças uma vida mais prazerosa no ambiente escolar.

o "Lúdico na educação infantil favorece o processo e o desenvolvimento do ensino e aprendizagem de nossas crianças? ” È preciso ressaltar que os jogos e brincadeiras é usado nas escolas com uma atividade de menor importância sem um objetivo aparente.

O trabalho será divido em três partes. Na primeiria fazemos umbreve históricoda educação infantil no Brasil citando como a criança era vista no passando, falando um pouco da creche e dos direitos adquiridos até os dias atuais.

$\mathrm{Na}$ segunda conceitua-se a palavra lúdico, do brinquedo, da brincadeira e dobrincar no processo de ensino e aprendizagem e também os jogos sendo essa uma atividade que desperta muito interesse no aluno.

E por último a importância do lúdico na educação infantil, onde podemos entender o quanto os jogos e brincadeira favorece o processo de aprendizagem sendo uma ferramenta facilitadora.

Assim, o presente trabalho de conclusão de curso foi elaborado através desse interesse e a partir de levantamento bibliográfico sobre a importância do lúdico na Educação Infantil, visto que é de suma importância para o desenvolvimento do processo de aprendizagem e, principalmente, da criança na fase da educação infantil, sendo esse artigo embasado segundo as ideias dos seguintes autores: Ferreira (2002), Passos (2013), Silva (2011), Lopes (2005), Kuhlmann (2005) e Ariés (198I). 
Portanto, conclui-se que a ludicidade, é uma ferramenta metodológica de fundamental importância para que professores, não somente da educação infantil, venha de maneira constante a estimular as crianças a trilharem caminhos que levem a novas experiências e aprendizados, sendo de fundamental importância para que o mesmo (professor) veja sempre nas menores conquistas idealizadas pelos próprios alunos, deve sempre vim com somas significativas de incentivo, onde deve ser sempre respeitada o tempoda criança e as suas necessidades.

\section{BREVE HISTÓRICO DA EDUCAÇÃO INFANTIL NO BRASIL}

O presente capítulo busca trazer uma visão breve da história da Educação Infantil no Brasil, sendo que nos primeiros anos de colonização, por parte dos responsáveis pelo processo da educação dentro do território brasileiro, não se havia os cuidados necessários, como se tem atualmente para poder cuidar da criança e seus avanços cognitivos, sensoriais emotores.

Para a elite brasileira, a educação dessa criança era realizada dentro do ambiente doméstico, onde seriam preparadas para poder serem chefes de família e dar continuidade no processo de gestão dos negócios da própria família e no caso das meninas, eram simplesmente ensinadas a serem boas esposas e boas mães.

Segundo Lopes (2005) salienta que os primeiros indícios de um sistema de ensino educacional brasileiro ocorreram com a chegada dos jesuítas no Brasil em 1549. Não era umaeducação voltada para criança, naquela época a preocupação jesuíta era puramente fundamentada no catolicismo e nesta época a educação erade exclusão visto que aos filhos dos colonizadores ofereciam o ensino de ler, escrever e contar e enquanto para os índios acontecia o processo de aculturação, ou seja, impregnar somente a cultura portuguesa e aos negros uma exclusão.

Com a chegada dos portugueses ao Brasil podemos observar que ascrianças eram vítimas de maus tratos, castigos severos.

Nos naufrágios, essas eram as que mais sofriam. Não tinha prioridade e de embarque nos momentos de fuga, nem tão pouco espaço disponível nas 
embarcações de menor porte. [...] As crianças que sobreviviam a todas essas situações ainda corriam o risco de ataque dos piratas e corsários, sendo escravizadas ou vendidas (LOPES, 2005, p. 16).

No período colonial brasileiro não havia uma concepção do que é sercriança e enquanto um ser indefeso deveria viver em companhia de sua família,ter direito à alimentação saudável, moradia com dignidade, ou seja, ter o direito deser criança.

Segundo Aries (198I) até o final do século XVII não havia o que podemos dizer de sentimento de infância, a criança era vista como um adulto em miniatura, ela vivia entre os adultos sem nenhuma distinção.

Não se pensava, como normalmente acreditamos hoje, que a criança já contivesse a personalidade de um homem. Elas morriam em grande número. [...] Essa indiferença era uma consequência direta e inevitável da demografia da época. Persistiu até o século XIX, no campo, na medida em que era compatível com o cristianismo, que respeitava na criança batizada a alma imortal[...] A criança era tão insignificante, tão mal entrada na vida, que não se temia que após a morte ela voltasse para importunar os vivos. [...]. (ARIÈS, i98i, p.57).

Diante dessa situação foi trazida da França para o Brasil, que já existia neste país desde o século XVIII as creches, porém agora com um caráter assistencialista, onde as mãesdeixavam seus filhos para poderem trabalhar.

"A creche é um termo Francês Creche, que equivale à manjedoura, presépio, foi uma das designações usadas para referir-se ao atendimento de guarda e educação fora da família acrianças pequenas”. (RUIZ, 20II, p4)

Segundo Kuhlmann (2005), A creche não era uma instituição de ensino, o seu foco principal era assistencial, era um lugar de cuidado de crianças, enquanto as mães trabalhavam, onde seus filhos estariam protegidos dos perigos das ruas, saudáveis e higiênicos.

O papel da creche é, primordialmente, o de assistir à criança que fica privada dos cuidados maternos em razão do trabalho da mãe fora do lar. A creche é uma obra auxiliar da família, cuida da criança para a família, sem desligá-la do lar. (KUHLMANN, 2005, p. 487).

Conforme Farias (2005) em paralelo a esse tipo de instituição assistencialista, em 1726 na Bahia, foi criada a primeira instituição de caráter assistencialista com um fim 
diferenciado, ou seja, que se chamava Roda dos expostos sendo um local onde eram deixadas as crianças indesejadas, eram a maioria brancas, mestiças e principalmente negras.

Neste local não havia condições de higiene o que levava a um grande número de mortalidade infantil, porque visto que essas crianças eram cuidadas junto com os doentes nas Santas Casas de Misericórdia. Esse fator propiciava quea maioria não chegasse a vida adultae as que alcançam uma idade mais avançadaeram exploradas. Neste local havia uma forma de educação que podemos chamarde subalternização do trabalho infantil onde as crianças maiores e de maior idade eram exploradas. Com o crescente processo de expansão urbana e aProclamaçãoda República no século XIX, as mulheres, mães de família, tiveram que ajudarseus maridos na renda familiar trabalhando em indústrias, tendo a necessidade dedeixar seusfilhos em algum lugar.

Criou-se uma nova oferta de emprego para as mulheres, mas aumentaramos riscos de maus tratos às crianças, reunidas em maior número, aos cuidados de uma única, pobre e despreparada mulher. Tudo isso, aliado a pouca comida e higiene, gerou um quadro caótico de confusão, que terminou no aumento de castigos e muita pancadaria, a fim de tornar as crianças mais sossegadas e passivas. Mais violência emortalidade infantil. (RIZZO, 2003, p. 3I).

Segundo o autor acima citado, as famílias não se importavam com os seus filhos a ponto de deixarem estes serem maltratados numa condição tal de desprezo chegando alguns serem abandonados. Atitudes assim geraram em algumas pessoas um sentimento de inconformidade com tal situação, levando a retirada desses seres indefesos para serem cuidados. Se para alguns essa uma solução viável encontrada, para outros foi a solução do que eles poderiam tomar como uma forma de limpar as ruas desses desvalidos.

Pensar essa criança, como um agente transformador, e sujeito histórico e social, ocorrem somente nos primeiros anos do século XX, com a criação e a elaboração do chamado Código do Menor, em 1927, mostrando os primeiros cuidados que a sociedade brasileira deveria tomar com a criança e ainda paracom aqueles que sofriam violência no ambiente doméstico, nas mais variadas formas.

No início do século XX, anos 1920 e início dos anos 1930, foi marcado por 
reivindicações dos operários por melhores condições de trabalho incluindo as mulheres que lutavam por um local perto do trabalho para deixarem seus filhos enquanto cumpriam sua jornada de trabalho. Foi criado então a creche da companhia de fiação e Tecidos Corcovado no Rio de Janeiro, a primeira creche brasileira para os filhos dos operários.

Segundo Oliveira (2005, p.96):

Sendo de propriedade das empresas, a creche e as demais instituições sociais eramusadas por elas nos ajustes das relações de trabalho. O fato de o filho da operária estar sendo atendido em instituições montadas pelas fábricas passou, até, a ser reconhecido por alguns empresários como algo vantajoso, por provocar um aumento de produção por parte das mães

A influência da industrialização e urbanização com o crescente processo de expansão urbana e a Proclamação da República no século XIX, conforme jáapresentamos anteriormente, levaram as mulheres mães de família a assumirem empregos fora do lar para ajudar seus maridos na renda familiar. Tal necessidadee atitude minimizava as condições financeiras familiares, porém gerava um outro problema, visto que ao adentrarem ao mercado de trabalho, trabalhando emindustrias, seus filhos não teriam atenção nem cuidado por seus genitores e estes deveriam ser deixados em algum lugar, surgindo as instituições deensino.

Segundo Oliveira, (2005, p,62) "A criança começou a ser vista como sujeito de necessidade e objeto de expectativa e cuidados situados em um período de preparação para ingresso no mundo dos adultos”. Passava-se aquela ideia de que realmente a criança deveria ser tratada como uma cópia fiel do adulto que a tinha em casa, e muito menos esse adulto nãotinha o menor cuidado com o seu próprio comportamento e as suas atitudes consideradas erradas para queservissem como exemplo, para condutas seguidas por essa criança no futuro. Apesar de se iniciar uma visão e discussão acerca da infância e o surgimento da necessidade de amparo às crianças de mães que passam a ser mão de obra no mercado de trabalho, o surgimento de instituições, de creches começaram a surgir, porém, sem as condições básicas de funcionamento, ou seja, não havia higiene, não tinham profissionais, quanto mais profissionais qualificados para o ensino, e nem a compreensão 
da importância

da valorização da cultura de cada criança.

Segundo Kishimoto (1986, p. 39):

[...] A péssima instalação da creche, a promiscuidade anti-higiênica de zocrianças, quase todas com menos de 5 anos, as fisionomias esquálidas daqueles pequenos mal alimentados, a atitude insensível do vigilante, tudo isso provocou em meu espírito algumas considerações sobre os benefícios que produziria a instalação de Creches nas vizinhanças das fábricas.

Dessa forma, de acordo com o crescimento das usinas e a necessidade do trabalho feminino, foram criadas novas unidades para apoiar mais crianças, no Brasil, sendo elas em São Paulo, Rio de Janeiro, e Distrito Federal. Foi em 1920 e I930, a educação começou a servista como grande importância.

Segundo Monarcha (200I, p. 19I):

A Escola Nova tem como proposta central o descolamento das atenções do professor para o educando. Valoriza os métodos ativos de ensino e aprendizagem, coloca criança como centro do processo educacional levando em conta seus interesses e necessidades, da ênfase a liberdade do aluno e confere importância aosestudos da psicologia experimental.

Esse processo histórico está diretamente associado ao período denominado

higienista que teve início no Brasil no fim do século XIX e início do século XX em que os médicos higienistas pregavam melhorar a qualidade da vida humana em todos os sentidos.

Na década de 1940 segundo Oliveira (2005), o governo (Governo Getúlio Vargas) começou a promover ações nas áreas de saúde, previdência e assistência. Segundo Oliveira, (2005, p.roo) “ as creches eram planejadas como instituição de saúde, com rotinas de triagem, lactário, pessoal de enfermagem, preocupação com a higiene do ambiente físico".

No ano de 1946 o Governo Federal cria a Legião Brasileira de Assistência (LBA), sendo essa entidade com funcionalidade para executar as políticas sociais da família,maternidade e infância.

Segundo Campos; Rosemberg; Ferreira, (1993, p.30)

A LBA foi criada em 1942, tendo como objetivo inicial amparar os convocados para a II Guerra Mundial e suas famílias. Porém, desde sua criação, suas metas 
previam sua fixação como instituição destinada a desenvolver serviço de assistência.

De acordo com Oliveira (2002) em ig6o há um crescente aumento da indústria e o crescimento urbano no Brasil provocando também a crescente empregabilidade da mulher nomercado de trabalho.

“[...] creches e parques infantis que atendiam crianças em período integral passaram a ser cada vez mais procuradas não só por operárias e empregadas domésticas, mas tambémpor trabalhadoras do comércio e funcionárias públicas. " (OLIVEIRA, 2002, p. I02), a necessidade de mulheres irem em busca de seu sustento se tornava cada vez mais comum, e ter com quem deixar essas crianças era algo que despertava preocupação e receio, de algo de errado possa a acontecer com essa criança, longe dos seus cuidados.

Em 196ı foi aprovado a Lei de Diretrizes e Bases Da Educação Nacional (Lei 4024/6I), onde foi incluída pela primeira vez, os jardins-de-infância, sendo queessa lei dizia:

Art. 23 - A educação pré-primária destina-se aos menores de até 7 anos e será ministrada em escolas maternais ou jardins-de-infância.

Art. 24 - As empresas que tenham a seu serviço mães de menores de sete anos serão estimuladas organizar e manter, por iniciativas próprias ou em cooperação com poderes públicos, instituiçõoes de educação pré- primárias (LDB,196I).

Mesmo assim com o jardins-de-infância incluído na LDB não havia uma preocupação do poder público. Em 197ı é aprovada a Lei 5692, onde se fala novamente da educação infantil. No parágrafo $2^{\circ}$, do art. 19 , diz que “ os sistemas valerão para as crianças de idade inferior a 7 anos que recebam conveniente educação em escolas maternais, jardins-de-infância ou instituições equivalentes ”. (LDB 5692/71).

Segundo Merisse (1997) no final da década de 1970, paralelo a década de 1980 ocorreu em São Paulo o “ Movimento de Lutas por Creche ”, que consistia naluta pelo direitoa creche para as crianças.

De acordo com Merisse:

O Movimento de luta por creches, sob influência do feminismo,apresentava suas reivindicações aos poderes públicos no contexto por direitos sociais e da 
cidadania, modificando e acrescendo significados à creche enquanto instituição. Esta começa a aparecer como um equipamento especializado para atender e educar a criança pequena, que deveria ser compreendida não mais como um mal necessário, mas como alternativa que poderia ser organizada de forma a ser apropriada e saudável para a criança, desejável à mulher e a família. A creche irá, então, aparecer como oserviço que é um direito da criança e da mulher, que oferece a possibilidade de opção por um atendimento complementa ao oferecido pela família e também desejável (I997, p. 49)

A Constituição Federal em 1988 assegura a criança de o a 6 anos o direito a creche epré-escolas. No artigo 208, inciso IV, diz que “ o dever do Estado com a educação será efetivado mediante a garantia de $[\ldots]$ atendimento em creche e pré-escola às crianças de zeroa seis anos de idade" (CF, I988).

Em 1990 o estatuto da criança e do adolescente e criada com o objetivo garantir o direito da criança ao atendimento em creches e em pré-escola

Segundo o art.54, inciso IV, o ECA salienta que as crianças de o a 6 anos deidade temtodo o direito de atendimento em creche e pré-escola.

E em 1996 com a reorganização da Lei de Diretrizes e Bases da Educação 9394/96, que vigora até o presente momento, trazendo como relevância o reconhecimento da Educação Infantil como primeira etapa da educação básica, definindo no título V, Capítulo II, seção II, Art. 30 que a Educação Infantil será oferecida em: "I - creches, ou entidades equivalentes, para crianças de 4 a 6 anosde idade " (LDB, 1996)

Nessa perspectiva da Educação Infantil enquanto educação direito de todose dever do estado e da família será promovida e incentivada com a colaboração da sociedade, visando ao pleno desenvolvimento da pessoa, seu preparo para exercício da cidadania e sua qualificação para o trabalho. (Brasil.1988).

Diante disto considera-se o desenvolvimento da criança um processo bastante importante onde também nos leva a pensar nos professores, na família, ena escola, que tem também estar presentes conhecimentos dessas crianças, o professor como mediador

trabalhando de forma lúdica e da família sempre participativa contribuindo assim para umensino e aprendizagem melhor.

Segundo a lei de Diretrizes e Bases da Educação Infantil Nacional (LDB 9394/96), artigo 3o, a educação infantil será oferecida em: 
I - creches, ou entidades equivalentes para crianças de atétrês anos de idade;

II - pré-escolas, para as crianças de quatro a seis anos deidade;

Art. 3r: Na educação infantil a avaliação far-se-á mediante acompanhamento e registro do seu desenvolvimento, sem o objetivo de promoção, mesmo para o acesso ao ensino fundamental.

Sendo assim pode-se entender em um breve histórico tudo o que a criança já passou até aqui para poder ter direitos, tanto de estudar, receber cuidados, atenção e higienização.

A história da Educação Infantil no Brasil passou por vários percalços até chegar a criação de leis que protegem a criança como o Estatuto da Criança e do Adolescente, Lei de Diretrizes e Base, o Referencial Curricular Nacional paraEducação Infantil e a criação do Ministério da educação, sendo de forma muito importante essas leis para o cuidado da criança até os dias atuais e hoje o BNCC.

\section{LÚDICO: CONCEPÇÕES}

Nosso percurso na formação docente levantou-se inúmeros questionamentos e interesses, dentre eles a importância do lúdico no processo de aprendizagem. Assim, sentimos a necessidade de aprofundarmos sobre o assuntoque desencadeou nossa pesquisa atual mais especificamente sobre o lúdico na Educação Infantil.

De acordo com o dicionário escolar da Academia Brasileira de Letras (20II), traz o significado da palavra Lúdico como: " [...] que se refere a jogos, brinquedos e divertimentos: o aspecto lúdico da aprendizagem."

De acordo com Ferreira (2002) lúdico pode ser tanto brincadeira que provoca divertimento por meio de alguma atividade quanto jogo, ação de jogar, disputar, onde se facilita a aprendizagem, ou seja, não podemos afirmar que o lúdico é jogo e nem brincadeira,mas sim uma junção dos dois que provoca a ação de divertimento.

Segundo Ferreira (2002, p. 12), 
Lúdico: Relativo a jogos, brinquedos e divertimento;

Brinquedo: I. Objeto para as crianças brincarem. 2. Jogo de Criança;

brincadeira; Brincar: I. Divertir-se infantilmente. 2. Divertir-se,

entreter-se.[...]

Brincadeira: I. Ato ou efeito de brincar. [...]

Jogo: I. Atividade física ou mental fundada em sistema de regras que definem a perda ou oganho. 2. Passatempo. [...] .

Conforme o autor (2002) podemos verificar um aglomerado de significados que a palavra Lúdico está ligada, seja no brinquedo, no brincar, na brincadeira e no jogo, pois de acordo com os ensinamentos de Passos (2013, p. 43):

[...] termo "lúdico" é apresentado de modo incisivo: serve de adjetivo correspondente à palavra Jogo. Desse modo, ao compreendermos aremissiva temos a compreensão de jogo definida como: dispêndio de atividade física ou mental que não tem um objetivo imediatamente útil, nem sequer definido, cuja razão de ser, para a consciência daquele que aele se entrega, é o próprio prazer queaí encontra.

Passos (2013) diz que apesar do jogo estar ligado ao lúdico este provocaao ser humano ou mesmo na criança o sentimento de prazer, ou seja, o jogo sem regras, o esforço da mente e o trabalho físico, só terá o objetivo de lazer e entretenimento, e sempre focando no processo de construção de ensino aprendizagem, onde essa criança deve ser sempre estimulada a buscar novas formas de conhecimento, tanto pelos professores quanto pela família.

Observa-se que no decorre da história de acordo com Kishimoto (2003) na antiga Grécia e inclusive em Roma já havia indícios de atividade lúdica, que podemos citar os jogoseducativos., que era visto como um momento de recreação entre todos para representar um momento de trégua entre todos os gregos e romanos, nos momentos de guerra.

Segundo Kishimoto (2002) afirma que os jogos passaram de geração em geração através da prática ficando na memória da criança, e que na Grécia e o Oriente os povos 
que viviam nestes lugares já brincavam de amarelinha, pipas e jogar pedrinhas, onde a criança brincava pelo prazer simplesmente de brincar.

De acordo com Wajskop (2009) a criança que brinca se apropria do conhecimento através da prática, por isso o espaço escolar deve fornecer ferramentas para construção da aprendizagem significativa.

O lúdico na educação na visão de Carvalho (1992, p,28):

(...) o ensino absorvido de maneira lúdica, passa a adquirir um aspecto significativo e afetivo no curso do desenvolvimento da inteligência dacriança, já que ela se modifica de ato puramente transmissor a atotransformador em ludicidade, denotando-se, portanto em jogo.

O lúdico, segundo Ferreira (1986), tem relação com jogos, brinquedos e divertimentos, ou seja, ele envolve os jogos, brinquedos e brincadeiras, de fato, esses termosrelacionam-se entre si, no entanto, seus significados e conceitos são distintos.

O lúdico segundo (ALMEIDA, 2008 apud SILVA, 20II, p.I2):

[...] se o termo tivesse ligado a sua origem, o lúdico estaria se referindo apenas aojogo, ao brincar, ao movimento espontâneo, mas passou a ser conhecido como traço essencialmente psicofisiológico, ou seja, uma necessidade básica da personalidade do corpo, da mente, no comportamento humano. As implicações das necessidades lúdicas extrapolaram as demarcações do brincar espontâneo de modo que a definição deixou de ser o simples sinônimo do jogo. O lúdico faz parte das atividades essenciais da dinâmica humana, trabalhando com a cultura corporal, movimento e expressão.

De acordo com o conceito estabelecido do que venha a ser a ludicidade, se torna necessário que venham a delimitar as limitações do chamado brincar espontâneo de que o lúdico venha a fazer parte do processo de construção do ensino-aprendizagem, assim Santos (2002), mostra que o lúdico é uma necessidade do próprio ser humano, e sem a interferênciada própria idade:

(...) uma necessidade do ser humano em qualquer idade e não pode ser vista apenas como diversão. $\mathrm{O}$ desenvolvimento do aspecto lúdico facilita a aprendizagem, o desenvolvimento pessoal, social e cultural, colabora para uma boa saúde mental, prepara para um estado interior fértil, facilita os processos de socialização, comunicação, expressão e construção de conhecimento. (SANTOS 2002, p. 12) 
Segundo Vygotsky (1988) a imaginação da criança se desenvolve por volta dos 3 anos. A criança atribui o significado ao brinquedo na forma que ela o vê atribuindo um outrosignificado, assim Vygotsky (1988) mostra que,

"No brinquedo, o pensamento está separado dos objetos e a ação surge das ideias enão das coisas: um pedaço de madeira torna-se um boneco eum cabo de vassoura torna-se um cavalo. A ação regida por regras começa a ser determinada pelas ideais e não pelos objetos. Isso representa uma tamanha inversão da relação da criança com a situação concreta, real e imediata, que é difícil subestimar seu pleno significado". (1988, p. III).

$\mathrm{Na}$ visão de Vygotsky (1991), o brincar está diretamente ligado a Infância da criançapor isso os jogos e brincadeiras devem ser explorados, também, dentro da sala de aula facilitando o desenvolvimento da criatividade, inventividade e interação com outras crianças.

No próximo capítulo será compreendido a importância do lúdico no processo metodológico da educação infantil.

\section{A IMPORTÂNCIA DO LÚDICO NA EDUCAÇÃO INFANTIL}

O lúdico na educação infantil incentiva a criança a gostar de brincadeiras e jogos auxiliando bastante em seu desenvolvimento em vários aspectos.

Segundo Maluf, (2012, p 13)

[...] as instituições de Educação Infantil precisam ser acolhedoras, atraentes, estimuladoras, acessíveis as crianças e ainda oferecercondições de atendimento as famílias, possibilitando a realização de ações socioeducacionais.

$\mathrm{Na}$ Educação Infantil segundo autor é muito importante levar a criança a construir seus saberes e acolher com o uso de atividades lúdicas. Segundo Dallabona e Mendes. “ O lúdico na Educação Infantil tem por objetivo oportunizar ao educador a compreensão do significado e da importância das atividades lúdicas na Educação infantil, procurando provoca-lo para que insira o brincar em seus projetos educativos ”.

De acordo com o Vygotsky (1984), ”as maiores aquisições de uma criança são conseguidas no brinquedo, aquisições que no futuro torna-se ao seu nível básico de ação real e moralidade". Segundo o autor as crianças vivem desafios através das brincadeiras, levando-as a usarem a imaginação.

Segundo Santos (1997), mostra que: 
O desenvolvimento do aspecto lúdico facilita a aprendizagem, o desenvolvimentopessoal, social e cultural, colabora para a saúde mental, prepara para um estado interior fértil, facilita os processos de socialização, comunicação, expressão e construção do conhecimento. (1997pı2).

Segundo o autor é importante proporcionar a criança um espaço que os fornece, jogos e brincadeiras, melhorando sua socialização com o próximo, entende-se a importância do brincar na vida de uma criança estimulando sua imaginação e curiosidade.

Para Ferreira (2003) brincar é "divertir-se, recrear-se, entreter-se com jogos infantil." Como grande ferramenta para o lúdico jogo o juntamente com as regras destacase no desenvolvimento da criança, ou seja, ajudando-as a se comunicar, ouvir, respeitar e interagiratravés do lúdico.

De acordo com Zanluchi (2005-p.9I) "A criança brinca daquilo que vive, expressa sua imaginação lúdica de seu dia-a-dia.”, o despertar da imaginação na infância incentiva a criança a não deixar de buscar novas experiências, entre as brincadeiras e os jogos, podendo filtrar todo o que se tem como novas formas de conhecimento. Segundo Carvalho (1992):

Desde muito cedo o jogo na vida da criança é de fundamental importância, pois quando ela brinca explora e manuseia tudo aquilo que está a sua volta através de esforços físicos e mentais e sem se sentir coagido pelo adulto. (p.i4).

Desse modo é importante destacar que nas series iniciais como a Educação infantil o lúdico tem um papel bastante importante tendo como instrumento os jogos e as brincadeiras, onde o educador pode usá-los para ensinar.

Segundo Rodrigues e Rosim (2007, p.II)

Quando a criança brinca e se relaciona com brinquedos educativos, ela élevada pela mediação do professor e a partir disso, ela cria, usa a imaginação e através disso ela começa a distinguir a diferença entre certo e errado assim ela começa a refletir e superar suas limitações.

Vygotsky (199I) vem também destacar como uma atividade de "faz de conta" ou até mesmo as que possuem regras, auxilia a criança em seu desenvolvimento. Existem diferentes formas de predominar-se o brincar onde segundo Negrine (I994, p.4I), podemos 
destacar:

As atividades lúdicas possibilitam fomentar a "resiliência", pois permitem a formação do autoconceito positivo; As atividades lúdicas possibilitam o desenvolvimento integral da criança, já que através destas atividades a criança se desenvolve afetivamente, convive socialmente e opera mentalmente. $O$ brinquedo e o jogo são produtos de cultura e seus usos permitem a inserção da criança na sociedade; Brincar é uma necessidadebásica assim como é a nutrição, a saúde, a habitação e a educação; Brincar ajuda a criança no seu desenvolvimento físico, afetivo, intelectual e social, pois, através das atividades lúdicas, a criança forma conceitos,relaciona ideias, estabelece relações lógicas, desenvolve a expressão oral e corporal, reforça habilidades sociais, reduz a agressividade, integra-se na sociedade constrói seu próprio conhecimento.

Segundo está citação de Negrine destaca-se que os jogos e brincadeiras transmite conhecimento, tendo como importante mediador os professores que trabalham na EducaçãoInfantil.

Destaca também Friedmann, (2012) o professor deve "possibilitar tempo espaço e materiais para brincarem, livremente, escutar o que as crianças têm a se dizer". É importante dizer que não somente o professor, mas também a instituição enxergue o lúdico como ferramenta importante no crescimento e desenvolvimento da criança.

De acordo com Referencial Curricular Nacional para a Educação Infantil VI(I998), "Nas brincadeiras as crianças transformam conhecimentos que já possuíram anteriormente em conceitos gerais com os que brinca."

Podem ser trabalhados na Educação Infantil, jogos e brincadeiras, onde se é permitido as crianças aprenderem ter limites e seguir regras. Segundo Vygotsky(I99I).com o brincar cria-se as zonas de desenvolvimento proximal, auxiliando no desenvolvimento cognitivo. Segundo Vygotsky (1998).

A distância entre o nível de desenvolvimento real, que se costuma determinar através da solução independente de problemas, e o nível de desenvolvimento potencial, determinado através da solução de problemas sobre a orientação de um adulto ou em colaboração com os companheiros mais capazes (p.97)

De acordo com Vygotsky a zona de desenvolvimento proximal (ZDP) ajuda a criança a realizar sozinho aquilo que ela deseja, sem ajuda de um adulto, sendo assim e muito importante destacar o papel do professor nestas atividades lúdicas para que seja 
auxiliador da criança, mostrando quais atividades podem ser feitas sozinhas ou em grupos, levando-a a criar autonomia ensinando com auxílio de jogos e brincadeiras.

Segundo Santos, (2004) “A criança que é estimulada a brincar com liberdade terá grandes possibilidades de se transformar num adulto criativo. (p.II4)", a liberdade é essencial para o desenvolvimento da criança para que possa compreender nessa questão queo aprender dentro dos ambientes formais einformais, devem sim ser prazerosos para essas crianças que estão em fases de descobertas

Sendo assim, percebe-se que as atividades lúdicas na Educação Infantil e compreendida por brincadeiras jogos e brinquedos que se é pensado por vários autores como de acordo com Bueno (2010) " o jogo para criança não é igual ao jogo dos adultos, pois é preciso pensar quea criança trata-se de um momento em que, em geral ocorre aprendizagem e em geral para o adulto é recreação" (p,24).

O brinquedo também tem sua importância na Educação Infantil segundo Caetano (2004) “ a história do brinquedo é vasta e multiforme, estando sempre associada a criança, contrapondo com o adulto onde prevalece a lógica do trabalho” (p.I8).

Segundo Bueno (2010, p 25):

Qualquer tipo de brinquedo traz consigo uma relação de aprendizagem, bem como educativa. Quando uma criança confecciona seu próprio brinquedo, aprende com o seu trabalho transformar matérias-primas oriundas da natureza em objetos novos, que vão se constituir em um novo objeto, ou seja, novo brinquedo.

\section{CONSIDERAÇÕES FINAIS}

Entende-se que a Educação é um direito de todos e, portanto, devemos ser fiscalizadores desses direitos adquiridos para a construção da criança que amanhã será um adulto bem moldado.

Diante do que foi apresentado o lúdico oportuniza a utilização de jogos e brincadeiras, alémd e estimular a criança no seu sintido inteclectual, e na sua psicomotrocidade, e o quanto esses são uma das ferramentas mais importante para o desenvolvimento infantil, bem como a criança no decorrer de suas vivências com jogos 
aprende de forma espontânea e prazerosa, visto que a criança está em constante aprendizado, Principalmente no que se refere à preparaçãopara enfrentar os desafios ao chegar a vida adulta de uma maneira mais natural e proveitosa.

Dessa forma, vale ressaltar que é de suma importância, o emprego da ludicidade do planejamento de professores na educação infantil e com isso não sepode deixar de lado que o desenvolvimento cognitivo, sensorial e motor dessa criança, onde através do poder do imaginário o desenvolvimento da oralidade (leitura e escrita), pode ser muito mais eficaz doque nos métodos tradicionalistas etotalmente respetivo, além de tornar todo o processod e ensino aprendizagem mais prazeroso.

Uma pequena incursão na concepção de criança no passado se faz necessária para que possamos compreender as mudanças no processo de aprendizagem relacionada a criança, visto que inicialmente era tida como um adulto em miniatura até mesmo sendo vestidas como os adultos, um sujeito sem direitos, inclusive dos cuidados necessários para sua sobrevivência. Essa incursãofacilita a realização de um paralelo com os dias atuais onde a criança tem alguns direitos garantidos como a LDB (1996) que regulamenta, por exemplo, o direito a creche, a constituição federal (Brasil 1988) que cita a Educação com direito social edever do estado e da família.

\section{REFERÊNCIAS}

ARIÉS, Philippe. História social da criança e da família. Rio de Janeiro: Zahar Editores, I98I.

BECHARA, Evanildo (organizador) Dicionário escolar da Academia Brasileira deLetras: Língua Portuguesa. São Paulo: Companhia Editora Nacional, 201 .

BUENO, Elizangela. Jogos e Brincadeiras na educação Infantil: ensinandode formalúdica. Londrina - PR, 2010.

BRASIL. Educação, Ministério e do Desporto, Secretaria de Educação Fundamental;Referencial Curricular Nacional para a Educação Infantil
Brasília
$\mathrm{MEC} / \mathrm{SEF}$
1998
$\mathrm{V}$
I. 
. Ministério da educação e cultura. Lei n 4 024. Brasília: MEC, i96ı. . Ministério da educação e cultura. Lei n 5 692. Brasília: MEC, I97ı. . Lei de Diretrizes e Bases da Educação Nacional n.o 9.394/96 Brasília DF, 1996. - Senado Federal. Constituição da República Federativa do Brasil. Brasília,Imprensa Oficial, Brasília:1998.

CAMPOS. M. M. ROSEMBERG. F. FERREIRA. I.M. Creches e pré-escolas no Brasil.

São Paulo: Cortez, 1993.

CUNHA, Nylse Helena Silva. Brinquedos, desafios e descobertas. Petrópolis,RJ: ed. Vozes, 2005.

CAETANO, Ricardo Jorge Bastos. Jogos, Brinquedos e Brincadeiras dos

Nossos Avôs: Um Estudo Do Gênero. Coimbra, 2004.

Disponível

em:https://estudogeral.sib.uc.pt/bitstream/ı0316/17563/ı/Monografia\%2ofinal.pdf. Acessoem: 04/05/2019.

DALLABONA, S.R.; MENDES, S.M.S O lúdico na Educação Infantil. Revista de divulgação técnico científica do ICPG, v.I, n.4, jan/mar 2004.

FARIAS Mabel. Infância e educação no Brasil nascente. In: VASCONCELLOS, Vera Maria Ramos de (Org.). Educação da infância: história e política. Rio de Janeiro: DP\&A,2005.

FERREIRA, A. B. de H. Novo Dicionário da Língua Portuguesa. 4. ed. Rio de Janeiro:Nova Fronteira, 2002.

. Novo Dicionário da Língua Portuguesa.2. ed. Rio de Janeiro:

NovaFronteira, 1986.

.Mini Aurélio Escolar Século XXI: o minidicionário da língua portuguesa. 4ed. Rio de Janeiro: Editora Nova Fronteira, 2003.

FRIEDMANN. Brincar na Educação Infantil: observação, adequação e inclusão. I⿳亠口冋 Ed.São Paulo; Moderna, 2012.

KISHIMOTO. O jogo e a educação infantil. São Paulo: Pioneira, 2003. - Jogo, brinquedo, brincadeira e a educação. São Paulo: Pioneira,2002 
KUHLMANN, Moysés. Educação Infantil no século XX. In: STEPHANOU, Maria; BASTOS, Maria Helena Câmara (Org.). História e memória da educação no Brasil. São Paulo: Vozes, 2005. v. 3.

LOPES, Jader Janer Moreira. Grumetes, pajens, órfãs do rei e outras crianças migrantes. In: VASCONCELLOS, Vera Maria Ramos de (Org.). Educação da infância: história e política. Rio de Janeiro: DP\&A, 2005, 13-30.

MALUF, Angela Cristina M. Atividades lúdicas para a educação infantil. Editora Vozes limitada, 2012.

MERISSE. A. Origem das instituições de atendimento à criança: o caso dascreches. In MERISSE. A et al. Lugares da infância: reflexão sobre a história da criança na fábrica,creche e orfanato. São Paulo. Arte e Ciência, 1997.

NEGRINE, Airton. Aprendizagem e desenvolvimento infantil. Porto Alegre: Prodil,1994.

OLIVEIRA. Z. M. R Educação infantil: fundamentos e métodos. São Paulo:

Cortez 2005.

OLIVEIRA, V.B. (ORG). Introdução In: O brincar e a criança do nascimento aosseis anos. Petrópolis: Vozes, 2000.

PASSOS, Marcos P. de. O ato lúdico de conhecer: a pesquisa como processo dialógico de apropriação de dispositivos informacionais e culturais. 2013. $125 \mathrm{f}$. Dissertação (Mestrado em Ciência da Informação) - Escola de Comunicações e Artes, Universidade de São Paulo, São Paulo.

RODRIGUES, Eliane; ROSIN, Sheila Maria. Infância e práticas educativas. São Paulo:Eduem; 2007.

RUIZ, Jucilene Souza. O surgimento da creche: uma construção social ehistórica. 2011. Acesso: 04 de maio de 2019 Disponível: www.5ebem.ufsc.br/trabalhos/eixo_2/eozb _ too4.pdf

SANTOS, Santa Marli Pires dos. O lúdico na formação do educador. 5 ed.Vozes,Petrópolis, 2002. 